\title{
Review
}

\section{What can the HLA transgenic mouse tell us about autoimmune diabetes?}

\author{
F. S. Wong ${ }^{1}$ L. Wen ${ }^{2}$ \\ ${ }^{1}$ Department of Pathology and Microbiology, School of Medical Sciences, University of Bristol, Bristol, UK \\ 2 Section of Endocrinology, Yale School of Medicine, New Haven, USA
}

\section{Abstract}

Type 1 diabetes mellitus is a polygenic disease strongly associated with the class II molecules DR3, 4 and the linked DQ2, 8 alleles. These molecules play an important role in presentation of peptide antigens after intracellular processing to CD4 T lymphocytes. A number of in vitro approaches have been used to elucidate the molecular basis for the association of particular HLA alleles with susceptibility to or protection from Type 1 diabetes mellitus. These have focused on the structure of the antigen-presenting molecules, together with their peptides. Binding studies, peptide elution, molecular modelling and crystallisation of the peptide MHC complex have between them made it possible to define the peptide-binding regions and to examine the stability of binding of peptides from putative autoantigens. It is difficult to study the role of these molecules in vivo in humans, and HLA transgenic mice have been generated to overcome this problem. Studies of mice expressing the HLA class II alleles associated with diabetes have shown that the presence of HLA molecules alone does not cause disease except in the presence of an islet "insult", even when this "insult" would in itself be insufficient to precipitate disease in the absence of the HLA class II transgene. HLA transgenic mice offer a way to elucidate the in vivo role of these molecules, and could help the development of targeted immunotherapy.

Keywords Autoimmunity - HLA · Transgenic mouse · Type 1 diabetes mellitus

\section{Introduction}

Type 1 diabetes occurs when the insulin-producing beta cells of the pancreas are destroyed by an immune response. Genetic susceptibility predisposes to diabetes, but its development is modified by environmental

Received: 7 January 2004 / Accepted: 27 July 2004

Published online: 2 September 2004

C) Springer-Verlag 2004

L. Wen $(\square)$

Section of Endocrinology, Yale School of Medicine,

333 Cedar Street, New Haven, CT 06520, USA

E-mail: li.wen@yale.edu

Tel.: +1-203-7857186, Fax: +1-203-7375558

Abbreviations: IA-2, insulinoma-associated antigen-2 . NOD, non-obese diabetic $\cdot$ RIP, rat insulin promoter .

Th1, T helper 1 cells $\cdot$ Th2, T helper 2 cells influences. Geographical variation in incidence [1] probably reflects genetic and environmental differences, but the increasing incidence of Type 1 diabetes [2] suggests changing environmental influences.

Although many gene regions have been implicated, few have been confirmed in large family studies [3]. In contrast, the importance of the MHC complex region on chromosome 6 that encodes HLA has been confirmed repeatedly. This susceptibility locus is designated IDDMI [4]. Different HLA molecules confer different kinds of susceptibility to autoimmune disease; some HLA molecules predispose to one disease but protect against another. The association with Type 1 diabetes is strongest with HLA class II molecules (DR, DQ and DP), although HLA Class I molecules also play a role, independently of linkage disequilibrium with HLA class II molecules [5]. Since there is tight linkage disequilibrium within the HLA class II region, it is often difficult to dissociate the effects of 
individual alleles (for example $D R$ ) from the effects of other alleles (for example $D Q$ ) that are co-inherited. A number of haplotypes have been linked to Type 1 diabetes [6, 7]. These include DRB1*0401-DQA1*0301/ $D Q B 1 * 0302$ (DR4/DQ8) and DRB1*0301-DQA1*0501/ $D Q B 1 * 0201$ (DR3/DQ2), which are often expressed together, especially in young patients $[8,9]$, and will be discussed further.

The specific biological function of MHC molecules is to allow products of an invading intracellular microorganism to be displayed on the cell surface in such a way as to be recognised by the immune system. $\mathrm{T}$ cells usually recognise antigens only after proteins have been processed through the antigen-processing machinery of cells. Although exceptions are increasingly recognised, exogenous proteins are generally processed through the endosomal pathway in specialised antigen-presenting cells such as B cells, dendritic cells and macrophages. The derived peptides are then presented on the surface of the cells by MHC class II molecules to CD4 T cells. Endogenous proteins are processed through the endoplasmic reticulum and presented in the context of MHC class I molecules, which are expressed on all cells.

A number of autoantigen targets for autoreactive $\mathrm{T}$ cells have been identified in newly diagnosed patients with Type 1 diabetes or in their close relatives. The most important of these include proinsulin (the precursor of insulin), insulin, the enzyme GAD and the tyrosine phosphatase, insulinoma-associated antigen 2 (IA-2) [10, 11, 12, 13]. Autoantibodies are important biological markers of the autoimmune process and are highly predictive of future disease in relatives of patients with diabetes [14]. The presence of autoantibodies suggests a pathogenic role for CD4 T cells, which recognise antigenic peptides presented by specific HLA class II molecules. CD4 T helper (Th) cells can be further divided into subpopulations 1 (Th1) and 2 (Th2) based on the cytokines they secrete. Th1 cells produce proinflammatory cytokines such as IFN- $\gamma$ and TNF- $\alpha$, whereas Th 2 cells secrete cytokines that promote antibody responses, such as IL-4, IL-5, IL-6 and IL-10.

Although HLA DQ molecules are more strongly associated with disease, most human $\mathrm{T}$ cell clones isolated from diabetic patients and specific for peptides of GAD [15, 16, 17, 18, 19], insulin [20] or I-A2 [21] are restricted to DR rather than DQ [22]. This may reflect the low level of HLA DQ expression on antigen-presenting cells or the fact that in vitro culture methods select for DR-restricted $\mathrm{T}$ cells. It is also possible that the pathogenic and DQ-restricted CD4 $\mathrm{T}$ cells are concentrated in or near the target organ (i.e. the pancreas) and are therefore not accessible for study.

The strength of genetic association studies has prompted considerable effort to investigate how these molecules predispose to Type 1 diabetes. This has been approached using peptide/MHC binding experiments [23], peptide elution from MHC molecules [24], molecular modelling [25] and crystallisation of the peptide-MHC complex [26]. These methods have made it possible to define the peptide-binding regions and to examine the stability of binding of peptides from putative autoantigens. It is not, however, possible to study the generation of peptides and the effect of administering peptides in vivo, nor to directly investigate the role of HLA class II on disease in humans. Animal models are required to dissect pathogenic processes and to investigate the effect of various therapeutic manipulations. This review will focus on "humanised" animal models, in the form of transgenic mice that express HLA molecules associated with autoimmune diabetes and other autoimmune disorders.

\section{What is a transgenic mouse?}

A transgenic mouse is produced by injecting cloned DNA fragments from the same or different species into a fertilised egg, which is then implanted into the uterus of a foster mother. The DNA integrates randomly into the genome, and there is no need for homology between the injected DNA and the host genome. Genomic DNA samples from the injected offspring of the foster mother are then examined for the expression of the injected DNA, usually by Southern blot or PCR. Offspring in which the injected DNA is stably integrated into the genome are then used as founders of a transgenic line (colony). Transgenic mice are often used to study targeted protein expression in a specific tissue (or cell type) by using a tissue-specific promoter in the cloned DNA fragment. The transgenic mice can then be used to evaluate the effect of expression of the protein.

\section{What happens if mice carry HLA genes?}

A large group of human diseases, including many autoimmune disorders, are associated with specific HLA genes. In transgenic mice, the expression of human HLA class II molecules on antigen-presenting cells in the thymus and periphery has a similar distribution to that of endogenous mouse MHC class II molecules. These models allow the function of the HLA molecules to be studied at a more fundamental level in vitro as well as in vivo. As a general rule, mice expressing HLA molecules do not develop spontaneous autoimmune disease, but in some cases a disease can be induced by injection of autoantigens.

The earliest autoimmune disease to be studied using HLA class II transgenic mice was collageninduced arthritis, in which collagen II is used to immunise mice and stimulate $\mathrm{T}$ and $\mathrm{B}$ cell responses [27]. Rheumatoid arthritis in humans is associated 
with HLA-DR1, DR4 and DQ8 and mice expressing these HLA molecules are susceptible to collageninduced arthritis, which shows many similarities with the human disease $[28,29]$. Studies using these HLA transgenic mice suggest that peptides derived from collagen II bound by DR molecules are important for the development of rheumatoid arthritis; these peptides may be important targets for prevention and/or treatment of the disease. Susceptibility to myasthaenia gravis in humans is strongly associated with the expression of HLA-DR3 and DQ8 but negatively linked to the expression of HLA-DQ6 molecules [30, 31, 32]. In vivo studies demonstrated that mice expressing transgenes for DR3 and/or DQ8 molecules developed experimental autoimmune myasthaenia gravis after immunisation with the human acetylcholine receptor, whereas DQ6 transgenic mice were resistant to induction of the disease [33]. Another disease associated with the expression of certain HLA molecules, particularly HLA-DR2, is multiple sclerosis. Experimental allergic encephalomyelitis can be induced in mice carrying the disease-susceptible HLA molecules by immunising them with myelin basic protein or myelin oligodendrocyte glycoprotein, autoantigens relevant to multiple sclerosis $[34,35]$.

HLA class II transgenic mice have offered good experimental models for the study of other autoimmune diseases, such as autoimmune thyroiditis, autoimmune uveitis and systemic lupus erythematosus [36, 37, 38, 39 ], and more recently human autoimmune myocarditis [40] and postinflammatory dilated cardiomyopathy [41]. These approaches have led to the generation of new animal models that may represent human diseases more closely than some of the currently existing models. These mice have also allowed the mapping of HLA-restricted $\mathrm{T}$ cell epitopes and investigation of the mechanisms underlying these genetic associations.

\section{Do HLA class II transgenic mice develop autoimmune diabetes?}

The non-obese diabetic (NOD) mouse has given us many insights into the pathogenesis of autoimmune diabetes, but the disease in NOD mice still differs in many respects from the human disease. Most mouse strains express the MHC class II molecules I-A and I-E, which are the human homologues of DQ and DR respectively. Whilst the only MHC class II molecule expressed in the NOD mouse ( $\left(\mathrm{I}^{-\mathrm{A}^{\mathrm{g}} 7}\right)$ is very similar to HLA-DQA1*0301/DQB1*0302 (DQ8), which predisposes to diabetes in humans, it is different from other human MHC class II molecules, e.g. DR3, DR4, DQ2, that also predispose to diabetes. Similarly, numerous other gene regions contribute to the development of diabetes in NOD mice, but do not necessarily correspond to the rest of the predisposing genes found in humans [42]. HLA transgenic mice allow us to study the role of the HLA with or without the presence of other potentially predisposing genes. The various HLA molecules have therefore been expressed on genetic backgrounds not susceptible to diabetes, such as $\mathrm{C} 57 \mathrm{BL} / 6$ or $\mathrm{C} 57 \mathrm{BL} / 10$. They have also been crossed on to an NOD background that does predispose to diabetes.

Although islet beta cell autoantibodies are important biological markers, islet-directed $\mathrm{T}$ cells are the primary immune mediators of beta cell destruction, acting via local release of cytokines, by direct cytolysis, or both. A patient who died soon after the onset of Type 1 diabetes showed insulitis composed of T cells, macrophages and B cells [43]. Pancreatic biopsy in newly diagnosed patients has identified both CD4 and CD8 T cells [44]. Recurrence of immune-mediated lesions in twin-to-twin pancreas grafts [45] and subsequent destruction of the graft further supports the role of $\mathrm{T}$ cells in disease development.

Studies from the NOD mouse have provided direct evidence that $T$ cells play a primary role. These mice develop insulitis at about 6 weeks of age and develop a disease similar to human Type 1 diabetes from 12 weeks onwards, with about $90 \%$ of females and $70 \%$ of males becoming diabetic by 30 weeks of age (data from the NOD mouse colony at Yale University). The central role of $\mathrm{T}$ cells in Type 1 diabetes is underscored by treatments designed to delete $\mathrm{T}$ cells using antibodies against CD3 that prevent disease in neonatal NOD mice [46]. In addition, adoptive transfer of T cells from diabetic mice into young or irradiated NOD mice or NOD/SCID mice produces disease [47, 48, 49]. It is now clear, at least in the animal models, that both CD4 and CD8 T cells play an important role in the development of disease. Diabetes does not occur in the absence of CD4 cells, as shown by studies using anti-CD4 antibodies in vivo [50], nor does it occur in mice that lack CD4 $\mathrm{T}$ cells due to genetic targeting [51]. NOD mice are also diabetes-free if they are deficient in CD8 $\mathrm{T}$ cells, either as a result of anti-CD8 antibody treatment in vivo [52] or as a result of genetic targeting $[53,54]$. These data indicate that both CD4 and CD8 T cells are necessary for the disease to develop.

$\mathrm{T}$ cells develop in the thymus and the expression of MHC class I and II molecules on thymic epithelial cells facilitates development of CD8 and CD4 T cells respectively. CD4 $\mathrm{T}$ cells require self-peptide presented by MHC class II molecules for their selection. If the appropriate MHC class II peptide complex is not available, the cells will die. If, however, the MHC class II peptide complex stimulates developing $\mathrm{T}$ cells too strongly, they then undergo negative selection. This process is important for production of the great diversity of $\mathrm{T}$ cells needed to recognise foreign antigens, whilst protecting against release of $\mathrm{T}$ cells that recognise self-antigens with high affinity (autoreactive). 
Table 1. The selection of murine CD4+ T cells in the presence or absence of human CD4 molecules

\begin{tabular}{|c|c|c|c|}
\hline Genotype & CD4+ T cells $(\%)$ & Background & Reference \\
\hline C57BL/6 & $56 \pm 8$ & C57BL/6 & {$[58]$} \\
\hline DQ8+/mII-/mCD4+/huCD4- & $15 \pm 5$ & $\mathrm{C} 57 \mathrm{BL} / 6$ & [58] \\
\hline DQ8+DR4+/mII-/mCD4+/huCD4- & $42 \pm 8$ & C57BL/6 & {$[79]$} \\
\hline DR3+/mII-/mCD4+/huCD4- & $28 \pm 6$ & C57BL/6 & Wen, unpublished data \\
\hline DQ8+DR3+/mII-/mCD4+/huCD4- & $48 \pm 8$ & C57BL/6 & Wen, unpublished data \\
\hline DQ8+DR3+/mII-/mCD4+/huCD4- & $14 \pm 1.5$ & N2 NOD & {$[60]$} \\
\hline DR4-/mII+/ mCD4+/huCD4- & 27 & Mixed & [55] \\
\hline DR4+/mII-/mCD4+/huCD4- & 3.8 & Mixed & {$[55]$} \\
\hline DR4+/mII-/mCD4+/huCD4+ & 13.3 & Mixed & {$[55]$} \\
\hline DR4+*/mII-/mCD4+/huCD4+* & 31.1 & Mixed & {$[55]$} \\
\hline DQ8+/ mII-/mCD4+/huCD4+ & 21 & NOD & [97] \\
\hline
\end{tabular}

This table only summarises the references that showed the actual number of CD4+ T cells in their system. Studies that did not publish the actual numbers are not included in the table.
Abbreviations: mII-, mouse MHC class II deficiency; mCD4+, mouse CD4; huCD4+, human CD4; huCD4-, no human CD4. * Homozygous for the indicated transgenes
The transgenic MHC class II molecules are expressed in the thymus as well as the periphery. This is important for selection of CD4 $\mathrm{T}$ cells that recognise peptides together with the human transgenic HLA molecules. In addition, the CD4 molecule increases the strength of the interaction between the $\mathrm{T}$ cell and the antigen-presenting cell in both the thymus and the periphery.

In HLA transgenic mice the MHC molecule is human but the other components, such as CD4, are of mouse origin. It has been argued that the interaction of the mouse CD4 molecule with the HLA-peptide-TCR complex may not be as strong as human CD4, potentially creating a problem in selection of CD4 T cells in the thymus of some HLA transgenic mice. It is therefore important that a sufficient number of CD4 T cells are selected by the human HLA molecules expressed in the mice, and some investigators have suggested that human CD4 molecules, expressed as transgenes, may be required in HLA transgenic mice $[55,56]$. It has, however, been shown that sufficient CD4 T cells can be selected in the thymus without human CD4, although the numbers may be lower than in in conventional mice. These $\mathrm{T}$ cells selected on human HLA molecules are functional in the presence of mouse CD4 and in the absence of human CD4 molecules [57, 58, 59, 60]. Altmann and co-workers [61] directly compared immune responses in HLA transgenic mice with or without a human CD4 transgene and found that the immune responses were not significantly different in these mice. Similarly, the expression of human CD4 in HLA-DQ8 mice on the NOD genetic background did not result in more effective autoimmunity to islet beta cells [62]. Table 1 summarises some of the studies.

The other potential confounding factor encountered in the study of human HLA transgenic mice is the pres- ence of endogenous mouse MHC class II molecules. If the HLA transgenes are expressed in addition to the endogenous mouse MHC class II molecules, these could interfere with and predominate over interactions with the transgenic HLA molecules. This pitfall can be overcome by breeding HLA transgenic mice together with mice that are deficient for mouse MHC class II (designated $\mathrm{I}_{-} \mathrm{A}^{\mathrm{b}}-/-$ or $\mathrm{mII}-$ ). This mutation in the mouse MHC class II molecule was originally specifically targeted to the I- $\mathrm{A}^{\mathrm{b}}$ molecule on the B6 genetic background [63]. For this knock-out mutation to be expressed in other genetic backgrounds, mII- mice must be backcrossed on to other strains.

Although HLA class II molecules play a key role in susceptibility to disease, other factors clearly play a role. It is therefore not surprising that the HLA transgenic animals that have been studied either in the presence or absence of endogenous mouse MHC class II do not spontaneously develop the HLA-associated diseases [58, 60]. This is also true when the HLA transgene is expressed on the NOD background [62] in the absence of the predisposing I-A $\mathrm{g} 7$. Importantly, however, both MHC class I and class II molecules are essential in determining susceptibility to disease; genes encoding class I and II molecules are often inherited together due to linkage disequilibrium. In mice deficient for endogenous MHC class II $\mathrm{I}^{-\mathrm{A}^{\mathrm{g}} 7}$ on the NOD genetic background, the mouse class II has been removed, but the MHC class I is also different due to linkage disequilibrium with the mutated MHC class II region. In this example, removal of the NOD I-Ag7 also results in a change of the NOD MHC class I molecules $\left(\mathrm{K}^{\mathrm{d}} \mathrm{D}^{\mathrm{b}}\right.$ to $\mathrm{K}^{\mathrm{b}} \mathrm{D}^{\mathrm{b}}$ expressed in the original $\mathrm{B} 6$ strain of mII-). Removal of $\mathrm{I}^{-\mathrm{A}^{\mathrm{g}} 7}$ in NOD mice thus also removes an important predisposing factor, $\mathrm{MHC}$ class $\mathrm{I}, \mathrm{K}^{\mathrm{d}}$, and this may contribute to the disease resistance found in HLA transgenic NOD mice. 
Table 2. Islet-beta-cell-associated antigenic peptides identified in HLA transgenic mice

\begin{tabular}{|c|c|c|c|}
\hline Peptides & Peptide sequence & HLA Restriction & Reference \\
\hline \multicolumn{4}{|l|}{ GAD } \\
\hline $21-40$ & ENPGTARAWCQVAQKFTGGI & DQ8 and DR3 & {$[69]$} \\
\hline $61-80$ & SVTSRAATGKVACTCDQKPC & DQ8 and DR3 & [69] \\
\hline $101-115$ & CDGERPTLAFLQDVM & DQ8 & {$[67]$} \\
\hline $115-127$ & MNILLQYVVKSFD & DR4 & [64] \\
\hline $201-220$ & NTNMFTYEIAPVFVLLEYVT & DQ8 & [62] \\
\hline $207-220$ & YEIAPVFVLLEYVT & DQ8 & [67] \\
\hline $231-250$ & PGGSGDGIFSPGGAISNMYA & DQ8 & {$[62]$} \\
\hline $248-267$ & AMMIARFKMFPEVKEKGMAA & DQ8 & {$[58]$} \\
\hline $261-280$ & VKEKGMAAVLPRLIAFTSEH & DQ8 & {$[64,69]$} \\
\hline $274-286$ & IAFTSEHSHFSLK & DR4 & {$[64]$} \\
\hline $521-535$ & ERMSRLSKVAPVIKA & DQ8 & {$[66]$} \\
\hline $536-550$ & RMMEYGTTMVSYQPL & DQ8 & {$[67]$} \\
\hline \multicolumn{4}{|c|}{ Preproinsulin } \\
\hline $1-24$ & MALWMRLLPLLALLALWGPDPAAA & DQ8 & {$[71]$} \\
\hline $11-26$ & LALLALWGPDPAAAFV & DR4 & {$[72]$} \\
\hline $20-36$ & PAAAFVNQHLCGSHLV & DR4 & {$[72]$} \\
\hline $44-63$ & GERGFFYTPKTRREAEDLQV & DQ8 & {$[71]$} \\
\hline $73-90$ & GAGSLQPLALEGSLQKRG & DR4 & {$[72]$} \\
\hline $85-101$ & SLQKRGIVEQCCTSICS & DR4 & [72] \\
\hline \multicolumn{4}{|l|}{ IA2 } \\
\hline $601-618$ & RQHARQQDKERLAALGPE & DQ8 & {$[73]$} \\
\hline
\end{tabular}

Despite the lack of spontaneous disease, these HLA transgenic models have proved very useful for the study of peptide binding to the HLA molecules, providing information about generation of immune responses to particular autoantigens in vivo and the binding of those autoantigenic peptides in vitro. These mice can generate efficient islet autoantigen-specific immune responses after immunisation with GAD and proinsulin, or peptides derived from these molecules. This has facilitated mapping of the peptide epitopes of GAD65 for HLA DR4 [64, 65], HLA DQ8 [62, 66, $67]$ and HLA DR3 [68, 69]. Although different studies do not necessarily identify the same epitopes, it is important to note that the genetic background (whether NOD or B6, B10) may also play a role in the outcome of immune responses [69, 70]. DQ8 transgenic mice also recognise epitopes of proinsulin [71, 72] and I-A2 [73]. Table 2 summarises the epitopes identified in these studies.

Despite the fact that HLA transgenic mice do not develop diabetes spontaneously, both DR3 and DQ8 transgenic mice have insulitis. When both of these predisposing molecules are present together in a mixed genetic background, insulitis increases [60]. There may, however, also be an environmental effect or an effect of the genetic composition, since DQ8 transgenic mice studied by different groups do not all have spontaneous insulitis [58]. Abraham and coworkers also demonstrated spontaneous GAD reactivity in DR3/DQ8 transgenic mice, although the autoreactive responses in DR3 or DQ8 transgenic mice alone are very low (all in mixed genetic background) [60]. In addition to the spontaneous or immunised responses seen to GAD, T cell lines have been generated that recognise GAD peptides 247-266 and 509-528 and are restricted by HLA DQ8 [58].

\section{Can an altered islet beta cell microenvironment promote spontaneous diabetes in HLA class II transgenic mice?}

Although the presence of MHC class II molecules may stimulate insulitis, it is not in itself sufficient to 
precipitate diabetes [60]. The presence of autoreactive $\mathrm{T}$ cells alone is also insufficient for disease development. DQ8-restricted Th1 CD4+ T cell lines, generated in DQ8 transgenic mice and specific for GAD peptides 247-266 and 509-528, failed to induce detectable islet pathology when adoptively transferred into DQ8 transgenic mice. This is not surprising considering that GAD65 is present at low levels in mouse islets, and that islet inflammation does not normally occur in HLA-transgenic mice.

Streptozotocin is a glucose analogue that is toxic to islet beta cells and can, in high doses, cause diabetes. Low-dose streptozotocin treatment has been used to cause damage to islets without precipitating insulitis or diabetes $[58,74]$, with a view to stimulating apoptosis of islets and increasing expression of islet antigens. GAD peptide-reactive cells generated in DQ8 transgenic mice induced severe insulitis after adoptive transfer if the recipients were treated with a very low dose of streptozotocin. They did not, however, precipitate diabetes [58]. In this situation, streptozotocin promoted the up-regulation of mouse MHC class I molecules $\left(\mathrm{K}^{\mathrm{b}}\right.$ and $\left.\mathrm{D}^{\mathrm{b}}\right)$ and human MHC class II molecules (DQ8) on splenocytes. Expression of the CD3 component of the T cell receptor and of the CD8 (but not CD4) co-receptor on T cells, and expression of the adhesion molecules ICAM-1 and VCAM-1 on the endothelial cells of the pancreas and epithelial cells of kidney tubules were all increased by streptozotocin [58]. These changes-particularly the upregulation of MHC class $\mathrm{I}$, of $\mathrm{T}$ cell markers (CD3 and CD8) on lymphocytes, and of adhesion molecules on endothelial or epithelial cells in the pancreatic islets-indicated that streptozotocin could facilitate the homing of GAD peptide-reactive $\mathrm{T}$ cells to their target tissue. CD8 T cells are very likely to be involved in this process. In contrast, neither the expression of costimulatory molecules (B7.1 and B7.2) nor of adhesion molecules (LFA-1, ICAM-1 and LPAM) on splenocytes was significantly affected by streptozotocin treatment [58].

\section{HLA class II transgenic RIP-B7.1 mice}

In the NOD mouse model (reviewed in [75]), CD4 $\mathrm{T}$ cells alone do not cause disease; CD8 T cells are also required. Similarly, there is evidence for CD8 involvement in human Type 1 diabetes, as discussed above. It is therefore possible that stimulation of the activity of CD8 T cells will also be needed to examine the effect of human HLA class II molecules in diabetes.

Experiments using streptozotocin indicate that a small amount of islet damage will induce severe insulitis but not diabetes in the presence of disease-predisposing MHC class II molecules. Full T cell activation is a multicomponent process that requires both stimu-

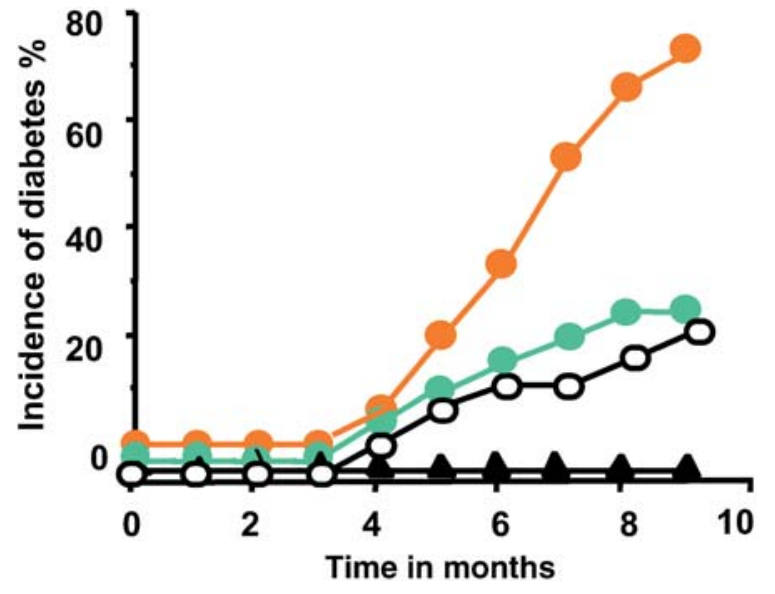

Fig. 1. Incidence of spontaneous diabetes development in HLA/RIP-B7.1 mice [77]. Four groups of mice were used in the study. Orange circles: DQ8/RIP.B7; turqoise circles: DR4/ RIP.B7; white circles: DQ8DR4/RIP.B7; black triangles: DQ6/ RIP.B7. Number of mice per group: 12 to 27 . The mice were housed in specific pathogen-free conditions and spontaneous diabetes development was monitored weekly by urine glucose and confirmed by blood glucose $(>13.9 \mathrm{mmol} / \mathrm{l})$. The experiments ended when the mice were over 9 months old

lation through the $\mathrm{T}$ cell receptor and also a second signal. The second signal needed for full activation of naïve $T$ cells results from the interaction of costimulatory molecules, such as B7.1 or B7.2, with CD28 on $T$ cells. To investigate whether activating islet-specific CD8 $\mathrm{T}$ cells would facilitate the development of diabetes, we generated DQ8+, mouse MHC class II(mII-) mice expressing the costimulator B7.1 molecule under the rat insulin promoter (RIP). These mice were designated DQ8+/RIP-B7.1 mice. RIP-B7-1 mice, which were originally generated on the B6 genetic background and carry mouse endogenous MHC class II I-A ${ }^{b}$ molecules, rarely develop diabetes [76]. Similarly, low rates of diabetes are seen in RIP.B7-1 mice in the absence of mouse MHC class II $[77,78]$. In striking contrast to these RIP-B7.1 B6 mice, substitution of human DQ8 molecules for the murine MHC class II caused RIP-B7.1 mice to develop spontaneous insulitis and a high incidence of diabetes, which appeared equally in both sexes, similar to humans [77, 79]. Spontaneous diabetes was also seen when murine MHC class II I-A $\mathrm{A}^{\mathrm{b}}$ molecules were replaced by human DR4 molecules in the presence of the RIP-B7.1 transgene, but no diabetes occurred when non-diabetessusceptible human MHC class II molecules were substituted: DQ6+/RIP-B7.1 mice do not develop diabetes (Fig. 1) [77]. Thus, in this HLA transgenic model system, the spontaneous development of diabetes specifically requires the expression of HLA alleles encoding molecules that impart susceptibility to diabetes, such as DQ8 or DR4. Interestingly, the site of DQ8 expression strongly influences the incidence of diabetes onset. Lipes, using the same RIP-B7.1 system, reported that high expression of DQ8 in the thymus resulted 


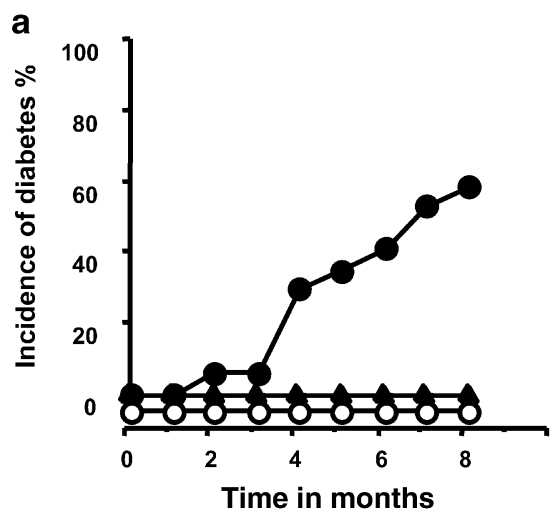

Fig. 2. Incidence of spontaneous diabetes development in DQ8/RIP-cytokine (TNF- $\alpha$ and IFN- $\alpha$ ) mice. The groups of mice used were (a) DQ8+ mII-/TNF- $\alpha^{+}$(filled circles); DQ8+ mII-/TNF- $\alpha-$ (filled triangles); DQ8- mII-/TNF- $\alpha^{+}$(open circles); and (b) DQ8+ mII-/INF- $\alpha^{+}$(filled circles); DQ8+ mII-/ INF- $\alpha$ - (filled triangles); DQ8- mII-/INF- $\alpha^{+}$(open circles). Number of mice per group: 15 to 20 . The mice were housed in specific pathogen-free conditions and spontaneous diabetes development was monitored weekly by urine glucose and confirmed by blood glucose $(>13.9 \mathrm{mmol} / \mathrm{l})$. The experiments ended when the mice were over 8 months old

in early onset and $100 \%$ incidence of diabetes in DQ8+/RIP-B7.1 mice [80]. In summary, expression of the RIP-B7-1 molecule is likely to have an effect on CD8 T cells. This effect, together with an appropriate stimulus for autoreactive CD4 $\mathrm{T}$ cells selected on diabetes-susceptible MHC class II molecules, is sufficient to facilitate the development of diabetes.

\section{HLA class II transgenic RIP-cytokine mice}

Costimulatory molecules (B7.1 and B7.2) are normally expressed on professional antigen-presenting cells, such as dendritic cells, B cells and macrophages, but not on pancreatic beta cells, even in the presence of inflammation [81]. In contrast, pro-inflammatory cytokines, such as TNF- $\alpha$ or IFN- $\alpha$, that can act as a local stimulus to both CD4 and CD8 T cells can be expressed in the islet upon exposure to infection or inflammatory stimuli. To test whether the local expression of cytokines, such as TNF- $\alpha$ or IFN- $\alpha$, could also precipitate diabetes, we expressed these molecules as transgenes in the islets. We replaced the B7.1 molecule on the islet beta cells with RIP-TNF- $\alpha$ [76] or IFN- $\alpha$ [82] using the same insulin promoter. This generated mice that expressed the HLA transgene, lacked mouse MHC class II molecules and expressed either TNF- $\alpha$ or INF- $\alpha$ in the islets, thus mimicking islet inflammation. Neither RIP-TNF- $\alpha$ nor RIP-IFN- $\alpha$ alone, expressed on a B6 background, caused spontaneous diabetes, but $60 \%$ (10/17) of DQ8+/RIP-TNF- $\alpha$ and $30 \%(6 / 20)$ of DQ8+/RIP-IFN- $\alpha$ mice developed diabetes in the presence of the DQ8 transgene (previ-

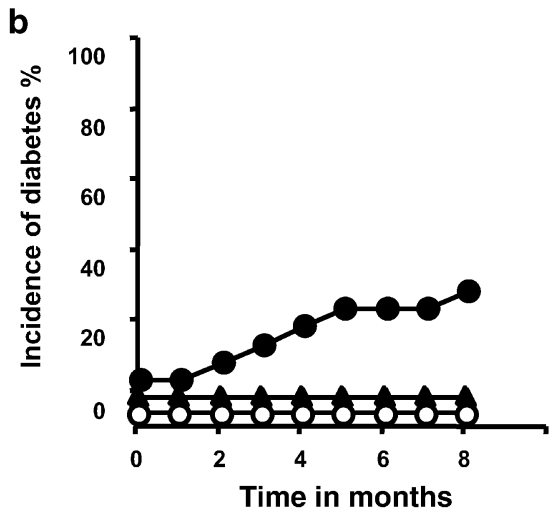

ously unpublished data, Fig. 2). As with the DQ8+/ RIP-B7.1 mice, the development of spontaneous diabetes was dependent on the presence of DQ8, since neither TNF- $\alpha$ nor IFN- $\alpha$ induced diabetes on this genetic background when expressed alone. These data also confirm that the presence of the HLA molecule alone is not sufficient for diabetes to develop spontaneously, and that an environmental stimulus is necessary to precipitate the disease. This is also true for the induced models of other human diseases such as collagen-induced arthritis and myelin basic proteininduced experimental allergic encephalomyelitis in HLA transgenic mice.

\section{Can the disease be transferred to normal syngeneic recipients?}

One of the definitions of a cell-mediated autoimmune disease is that the disease can be adoptively transferred by lymphocytes. To ascertain whether the spontaneous diabetes in HLA transgenic model systems is mediated by $\mathrm{T}$ cells, we performed a series of adoptive transfer experiments, which showed that diabetes in these model systems is indeed cell-mediated. Interestingly, in the HLA/RIP-B7.1 system diabetes could only be transferred to recipients that also express B7.1 on islet beta cells $[77,79,80]$. This is in contrast to the HLA/RIP-cytokine system, in which diabetes could be transferred to the recipients regardless of whether the cytokine is expressed on islet beta cells (previously unpublished data, Table 3).

\section{What is the individual and combinatorial role of DQ and DR molecules in predisposition to diabetes?}

HLA-DR4 (0401)/DQ8 and -DR3/DQ2 are common haplotypes in Type 1 diabetes, but it is difficult to study their individual roles in disease development because of linkage disequilibrium within the MHC, such as DQ8 with DR4 or DQ2 with DR3. Transracial studies have shown that particular DQ molecules may not necessarily be associated with the same DR molecules as found in Caucasoid populations [83]. It is therefore 
Table 3. Adoptive transfer diabetes from diabetic donors to non-diabetic recipients

\begin{tabular}{llr}
\hline Irradiated recipients & Diabetic donors & Diabetes development \\
\hline DQ8+mII-/RIP-TNF- $\alpha+$ & DQ8+mII-/RIP-TNF- $\alpha+$ & $100 \%(n=8)$ \\
DQ8+mII-/RIP-TNF- $\alpha-$ & DQ8+mII-/RIP-TNF- $\alpha+$ & $100 \%(n=8)$ \\
DQ8-mII-/RIP-TNF- $\alpha-$ & DQ8+mII-/RIP-TNF- $\alpha+$ & $0 \%(n=6)$
\end{tabular}

Splenocytes were prepared from diabetic mice and transferred intravenously into irradiated non-diabetic recipients $\left(10 \times 10^{7 /}\right.$ recipient). Diabetes development in the recipients was moni-

interesting that the combination of the DR3-DQ2 and DR4-DQ8 heterozygous genotype promotes diabetes more strongly than the DR4-DQ8 homozygous genotype. This phenomenon has been attributed to transcomplementation of the class II molecules such that, for instance, the $\alpha$ chain encoded by DQA $1 * 0301$ (DQ8 $\alpha$ chain) may pair with the $\beta$ chain encoded by DQB1*0201 (DQ2 $\beta$ chain) and the $\alpha$ chain of DQA $1 * 0501$ (DQ2 $\alpha$ chain) pairs with the $\beta$ chain encoded by DQB $1 * 0302$ (DQ8 $\beta$ chain) $[84$, $85]$. It is possible to study transgenic mice carrying one or multiple HLA gene(s) individually or in combination. Using this approach, one study [60] showed that DQ8/DR3 double transgenic mice (on B6/129/B10 mixed genetic background) developed more insulitis than either DQ8 or DR3 single transgenic mice. Conversely, another study [79], using RIP.B7.1 mice (on B6 genetic background) coexpressing DQ8 and DR4, found functional evidence for a primary role of DQ8 and a possible regulatory role of DR4 in the pathogenesis of autoimmune diabetes. Kudva and co-workers [86] have also demonstrated more insulitis in DQ8/NOD mice than in DR3/NOD mice. In this instance the frequency and severity of insulitis in DQ8/DR3 double transgenic NOD mice were similar to that seen in DR3/NOD mice. It thus appeared that DR3 transgene expression decreased the frequency/severity of insulitis found in DQ8/NOD mice, as in the DR4/RIP-B7.1 system on the B6 genetic background [79]. This phenomenon has also been suggested in humans [87]. Genetic studies of patients with diabetes show that DR4 subtypes confer varying degrees of protection that modify the risk mediated by DQ8 [88, 89]. HLA transgenic mice thus provide insight into the way in which some HLA genes may regulate the effects of others.

\section{Are HLA class I transgenic mice useful in the study of human disease?}

The two most studied HLA class I transgenic mice are HLA-A2.1 and HLA-B27 mice. These have been used in studies of CD8 cytolytic T cells in response to viral infection, such as HIV [90, 91], HCV [92, 93] or influenza virus [94], and to tumour invasion $[95,96]$. As with HLA class II transgenic mice, HLA-A2.1 and tored and determined by urinary glucose and confirmed by blood glucose (>13.9 mmol/l)

B27 mice are important tools for identification and characterisation of viral or tumour antigenic epitopes for CD8 T cells, and for preclinical evaluation of vaccines against viruses and for cancer immunotherapy. HLA-B27 transgenic mice have been used as a good animal model for human spondyloarthropathies. These mice develop spontaneous inflammatory disease resembling human arthropathies, and disease development is under the influence of the gut bacterial flora, as in humans [97, 98].

Although there has been a much greater focus on MHC class II in susceptibility to Type 1 diabetes, it has in recent years become clear that CD8 $\mathrm{T}$ cells restricted by MHC class I also play an important role in pathogenesis of disease. Whilst the HLA class I genetic association with diabetes is not as strong as with MHC class II, a number of alleles are commonly expressed in patients with diabetes [5, 99]. The only in vivo study in diabetes to date has been the investigation of the effect of HLA-A2.1 as a transgene crossed on to the NOD background [100]. This HLA transgene was coexpressed with mouse MHC class I $\left(\mathrm{K}^{\mathrm{d}} \mathrm{D}^{\mathrm{b}}\right)$ and II (I-A $\left.\mathrm{A}^{\mathrm{g}}\right)$ molecules, and an acceleration of diabetes was shown in the presence of the transgene. This is clearly an area of importance and the effect of such transgenes should be examined in the absence of mouse MHC class I molecules (particularly $\mathrm{K}^{\mathrm{d}}$ ) known to predispose to diabetes.

\section{Concluding remarks}

HLA transgenic mice have provided new models of immune-mediated diabetes to complement studies in the NOD mouse. They are useful for mapping epitopes of putative autoantigens. The fact that they do not develop spontaneous diabetes limits their capacity for use in testing of interventions to prevent diabetes, but combined transgenic models such as the HLA transgenic mice that coexpress cytokines or costimulatory molecules on the pancreatic beta cells do develop spontaneous disease. This makes it clear that both autoreactive $\mathrm{T}$ cells and islet-related factors are important, as summarised in Figure 3. These mice also show that, in the presence of islet-related factors, the predisposing HLA molecule determines whether the disease develops, which accords well with the 


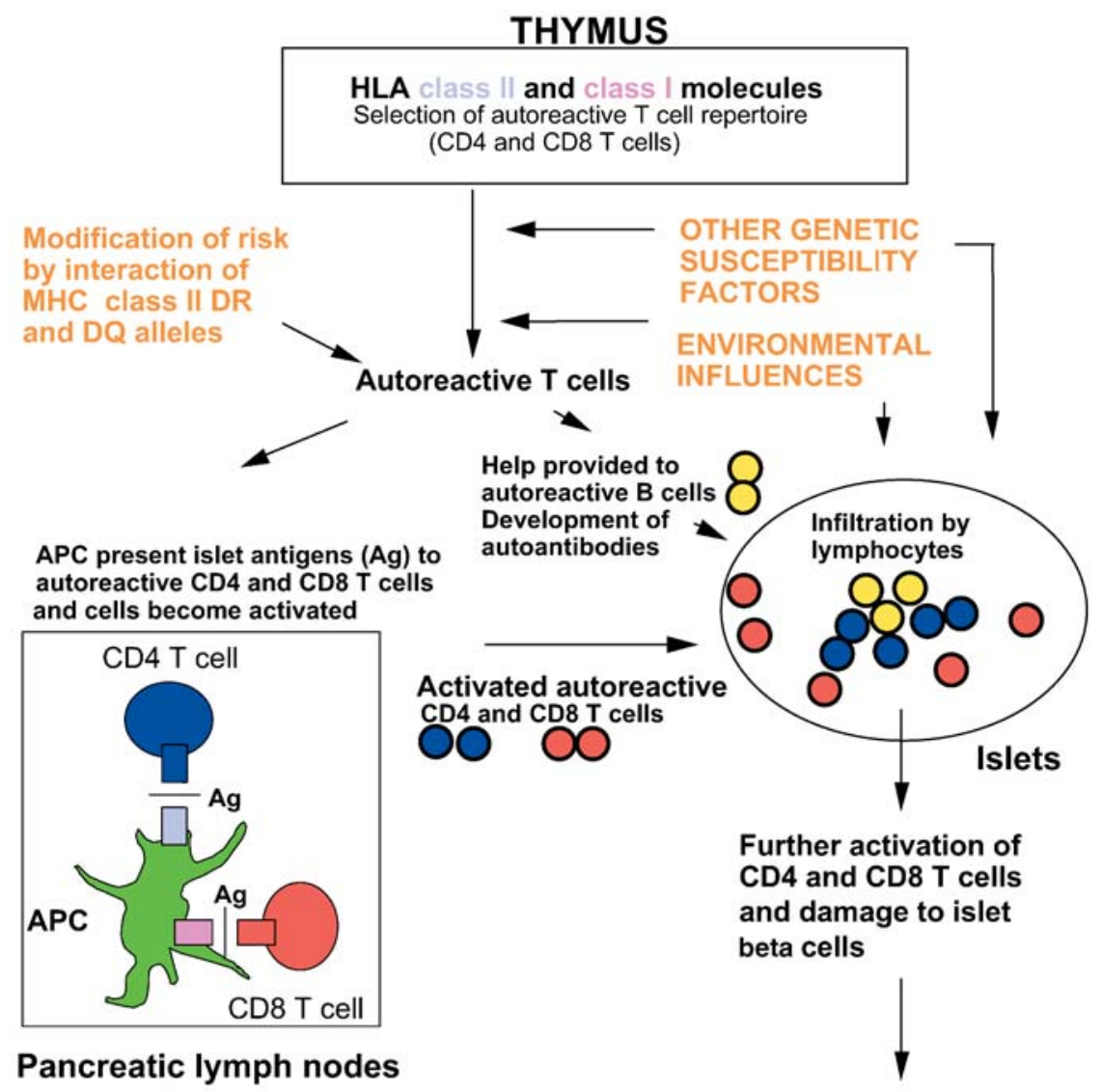

\section{DIABETES}

Fig. 3. Hypothetical scheme representing development of Type 1 diabetes and incorporating factors that play a role in disease development. APC, antigen-presenting cells

view that islet abnormalities contribute to autoimmune diabetes [101]. Suitably modified HLA transgenic mice could therefore be used in studies of diabetes prevention. Since patients may not express some of the molecules used as transgenes in the pancreatic beta cells, it might be argued that these are artificial models, which do not relate to the human disease. This argument, however, applies to all animal models, which inevitably differ from humans in some respects. Nevertheless, one very important future use of these HLA transgenic mice will be in the study of agents such as tolerising peptides; if such an immunological intervention is effective, this would greatly strengthen the rationale for its use in the human disease.

As the development of immunotherapy to treat and prevent Type 1 diabetes proceeds, putative therapies will need to be tested in more than one model, especially as so many manipulations influence the development of diabetes in the frequently studied NOD mouse [102]. The challenge will be to translate findings in animal models to human disease.
Acknowledgements. F.S. Wong is a Wellcome Trust Senior Fellow in Clinical Science. L. Wen was recipient of a Career Development Award from the Juvenile Diabetes Foundation International. This work was also funded by NIH (AI 44427).

\section{References}

1. Karvonen M, Viik-Kajander M, Moltchanova E, Libman I, LaPorte R, Tuomilehto J (2000) Incidence of childhood type 1 diabetes worldwide. Diabetes Mondiale (DiaMond) Project Group. Diabetes Care 23:1516-1526

2. Onkamo P, Vaananen S, Karvonen M, Tuomilehto J (1999) Worldwide increase in incidence of Type I diabetes-the analysis of the data on published incidence trends. Diabetologia 42:1395-1403

3. Cox NJ, Wapelhorst B, Morrison VA et al. (2001) Seven regions of the genome show evidence of linkage to type 1 diabetes in a consensus analysis of 767 multiplex families. Am J Hum Genet 69:820-830

4. Davies JL, Kawaguchi Y, Bennett ST et al. (1994) A genome-wide search for human type 1 diabetes susceptibility genes. Nature 371:130-136

5. Fennessy M, Metcalfe K, Hitman GA et al. (1994) A gene in the HLA class I region contributes to susceptibility to IDDM in the Finnish population. Childhood Diabetes in Finland (DiMe) Study Group. Diabetologia 37:937-944

6. Sanjeevi CB, Landin-Olsson M, Kockum I, Dahlquist G, Lernmark A (1995) Effects of the second HLA-DQ haplotype on the association with childhood insulin-dependent diabetes mellitus. Tissue Antigens 45:148-152 
7. Ronningen KS, Keiding N, Green A (2001) Correlations between the incidence of childhood-onset type I diabetes in Europe and HLA genotypes. Diabetologia 44 [Suppl 3]: B51-B59

8. Caillat-Zucman S, Garchon HJ, Timsit J et al. (1992) Agedependent HLA genetic heterogeneity of type 1 insulindependent diabetes mellitus. J Clin Invest 90:2242-2250

9. Tait BD, Harrison LC, Drummond BP, Stewart V, Varney MD, Honeyman MC (1995) HLA antigens and age at diagnosis of insulin-dependent diabetes mellitus. Hum Immunol 42:116-122

10. Palmer JP, Asplin CM, Clemons P et al. (1983) Insulin antibodies in insulin-dependent diabetics before insulin treatment. Science 222:1337-1339

11. Baekkeskov S, Aanstoot HJ, Christgau S et al. (1990) Identification of the $64 \mathrm{~K}$ autoantigen in insulin-dependent diabetes as the GABA-synthesizing enzyme glutamic acid decarboxylase. Nature 347:151-156 (Erratum [1990] Nature 347:782)

12. Hawkes CJ, Wasmeier C, Christie MR, Hutton JC (1996) Identification of the $37-\mathrm{kDa}$ antigen in IDDM as a tyrosine phosphatase-like protein (phogrin) related to IA-2. Diabetes 45:1187-1192

13. Solimena M, Dirkx R Jr, Hermel JM et al. (1996) ICA 512, an autoantigen of type I diabetes, is an intrinsic membrane protein of neurosecretory granules. Embo J 15:2102-2114

14. Bingley PJ, Williams AJ, Gale EA (1999) Optimized autoantibody-based risk assessment in family members. Implications for future intervention trials. Diabetes Care 22:17961801

15. Lohmann T, Leslie RD, Londei M (1996) T cell clones to epitopes of glutamic acid decarboxylase 65 raised from normal subjects and patients with insulin-dependent diabetes. J Autoimmun 9:385-389

16. Tabata H, Kanai T, Yoshizumi H et al. (1998) Characterization of self-glutamic acid decarboxylase 65-reactive CD4+ T-cell clones established from Japanese patients with insulin-dependent diabetes mellitus. Hum Immunol 59:549-560

17. Ou D, Jonsen LA, Metzger DL, Tingle AJ (1999) CD4+ and CD8+ T-cell clones from congenital rubella syndrome patients with IDDM recognize overlapping GAD65 protein epitopes. Implications for HLA class I and II allelic linkage to disease susceptibility. Hum Immunol 60:652-664

18. Ou D, Mitchell LA, Metzger DL, Gillam S, Tingle AJ (2000) Cross-reactive rubella virus and glutamic acid decarboxylase (65 and 67) protein determinants recognised by $\mathrm{T}$ cells of patients with type I diabetes mellitus. Diabetologia 43:750-762

19. Schloot NC, Willemen SJ, Duinkerken G, Drijfhout JW, de Vries RR, Roep BO (2001) Molecular mimicry in type 1 diabetes mellitus revisited: T-cell clones to GAD65 peptides with sequence homology to Coxsackie or proinsulin peptides do not crossreact with homologous counterpart. Hum Immunol 62:299-309

20. Schloot NC, Willemen S, Duinkerken G, de Vries RR, Roep BO (1998) Cloned T cells from a recent onset IDDM patient reactive with insulin B-chain. J Autoimmun 11:169175

21. Hawkes CJ, Schloot NC, Marks J et al. (2000) T-cell lines reactive to an immunodominant epitope of the tyrosine phosphatase-like autoantigen IA-2 in type 1 diabetes. Diabetes 49:356-366

22. Durinovic-Bello I, Steinle A, Ziegler AG, Schendel DJ (1994) HLA-DQ-restricted, islet-specific T-cell clones of a type I diabetic patient. T-cell receptor sequence similarities to insulitis-inducing $\mathrm{T}$ cells of nonobese diabetic mice. Diabetes 43:1318-1325
23. Yu B, Gauthier L, Hausmann DH, Wucherpfennig KW (2000) Binding of conserved islet peptides by human and murine MHC class II molecules associated with susceptibility to type I diabetes. Eur J Immunol 30:2497-2506

24. Peakman M, Stevens EJ, Lohmann T et al. (1999) Naturally processed and presented epitopes of the islet cell autoantigen IA-2 eluted from HLA-DR4. J Clin Invest 104:14491457

25. Moustakas AK, Routsias J, Papadopoulos GK (2000) Modelling of the MHC II allele I-A(g7) of NOD mouse: $\mathrm{pH}$-dependent changes in specificity at pockets 9 and 6 explain several of the unique properties of this molecule. Diabetologia 43:609-624

26. Lee KH, Wucherpfennig KW, Wiley DC (2001) Structure of a human insulin peptide-HLA-DQ8 complex and susceptibility to type 1 diabetes. Nat Immunol 2:501-507

27. Brand DD, Kang AH, Rosloniec EF (2003) Immunopathogenesis of collagen arthritis. Springer Semin Immunopathol 25:3-18

28. Bradley DS, Nabozny GH, Cheng S et al. (1997) HLADQB1 polymorphism determines incidence, onset, and severity of collagen-induced arthritis in transgenic mice. Implications in human rheumatoid arthritis. J Clin Invest 100:2227-2234

29. Holmdahl R, Andersson EC, Andersen CB, Svejgaard A, Fugger L (1999) Transgenic mouse models of rheumatoid arthritis. Immunol Rev 169:161-173

30. Bell J, Rassenti L, Smoot S et al. (1986) HLA-DQ betachain polymorphism linked to myasthenia gravis. Lancet 1:1058-1060

31. Carlsson B, Wallin J, Pirskanen R, Matell G, Smith CI (1990) Different HLA DR-DQ associations in subgroups of idiopathic myasthenia gravis. Immunogenetics 31:285-290

32. Djabiri F, Caillat-Zucman S, Gajdos P et al. (1997) Association of the AChRalpha-subunit gene (CHRNA), DQA $1 * 0101$, and the DR3 haplotype in myasthenia gravis. Evidence for a three-gene disease model in a subgroup of patients. J Autoimmun 10:407-413

33. Yang H, Goluszko E, David C et al. (2002) Mapping myasthenia gravis-associated $\mathrm{T}$ cell epitopes on human acetylcholine receptors in HLA transgenic mice. J Clin Invest 109:1111-1120

34. Madsen LS, Andersson EC, Jansson L et al. (1999) A humanized model for multiple sclerosis using HLA-DR2 and a human T-cell receptor. Nat Genet 23:343-347

35. Vandenbark AA, Rich C, Mooney J et al. (2003) Recombinant TCR ligand induces tolerance to myelin oligodendrocyte glycoprotein 35-55 peptide and reverses clinical and histological signs of chronic experimental autoimmune encephalomyelitis in HLA-DR2 transgenic mice. J Immunol 171:127-133

36. Flynn JC, Wan Q, Panos JC et al. (2002) Coexpression of susceptible and resistant HLA class II transgenes in murine experimental autoimmune thyroiditis: DQ8 molecules downregulate DR3-mediated thyroiditis. J Autoimmun 18:213-220

37. Wan Q, Shah R, Panos JC, Giraldo AA, David CS, Kong YM (2002) HLA-DR and HLA-DQ polymorphism in human thyroglobulin-induced autoimmune thyroiditis: DR3 and DQ8 transgenic mice are susceptible. Hum Immunol 63:301-310

38. Pennesi G, Mattapallil MJ, Sun SH et al. (2003) A humanized model of experimental autoimmune uveitis in HLA class II transgenic mice. J Clin Invest 111:1171-1180

39. Paisansinsup T, Vallejo AN, Luthra H, David CS (2001) HLA-DR modulates autoantibody repertoire, but not mortality, in a humanized mouse model of systemic lupus erythematosus. J Immunol 167:4083-4090 
40. Elliott JF, Liu J, Yuan ZN et al. (2003) Autoimmune cardiomyopathy and heart block develop spontaneously in HLA-DQ8 transgenic IAbeta knockout NOD mice. Proc Natl Acad Sci USA 100:13447-13452

41. Bachmaier K, Neu N, Yeung RS, Mak TW, Liu P, Penninger JM (1999) Generation of humanized mice susceptible to peptide-induced inflammatory heart disease. Circulation 99:1885-1891

42. Wicker LS, Todd JA, Peterson LB (1995) Genetic control of autoimmune diabetes in the NOD mouse. Annu Rev Immunol 13:179-200

43. Bottazzo GF, Dean BM, McNally JM, MacKay EH, Swift PG, Gamble DR (1985) In situ characterization of autoimmune phenomena and expression of HLA molecules in the pancreas in diabetic insulitis. N Engl J Med 313:353-360

44. Itoh N, Hanafusa T, Miyazaki A et al. (1993) Mononuclear cell infiltration and its relation to the expression of major histocompatibility complex antigens and adhesion molecules in pancreas biopsy specimens from newly diagnosed insulindependent diabetes mellitus patients. J Clin Invest 92:23132322

45. Sutherland DE, Sibley R, Xu XZ et al. (1984) Twin-to-twin pancreas transplantation: reversal and reenactment of the pathogenesis of type I diabetes. Trans Assoc Am Physicians 97:80-87

46. Hayward AR, Shreiber M (1989) Neonatal injection of CD3 antibody into nonobese diabetic mice reduces the incidence of insulitis and diabetes. J Immunol 143:1555-1559

47. Wicker LS, Miller BJ, Mullen Y (1986) Transfer of autoimmune diabetes mellitus with splenocytes from nonobese diabetic (NOD) mice. Diabetes 35:855-860

48. Miller BJ, Appel MC, O’Neil JJ, Wicker LS (1988) Both the Lyt-2+ and L3T4+ T cell subsets are required for the transfer of diabetes in nonobese diabetic mice. J Immunol 140:52-58

49. Rohane PW, Shimada A, Kim DT et al. (1995) Isletinfiltrating lymphocytes from prediabetic NOD mice rapidly transfer diabetes to NOD-scid/scid mice. Diabetes 44:550-554

50. Shizuru JA, Taylor-Edwards C, Banks BA, Gregory AK, Fathman CG (1988) Immunotherapy of the nonobese diabetic mouse: treatment with an antibody to T-helper lymphocytes. Science 240:659-662

51. Mora C, Wong FS, Chang CH, Flavell RA (1999) Pancreatic infiltration but not diabetes occurs in the relative absence of MHC class II-restricted CD4 T cells: studies using NOD/CIITA-deficient mice. J Immunol 162:4576-4588

52. Wang B, Gonzalez A, Benoist C, Mathis D (1996) The role of CD8+ T cells in the initiation of insulin-dependent diabetes mellitus. Eur J Immunol 26:1762-1769

53. Serreze DV, Leiter EH, Christianson GJ, Greiner D, Roopenian DC (1994) Major histocompatibility complex class I-deficient NOD-B2mnull mice are diabetes and insulitis resistant. Diabetes 43:505-509

54. Wicker LS, Leiter EH, Todd JA et al. (1994) Beta 2-microglobulin-deficient NOD mice do not develop insulitis or diabetes. Diabetes 43:500-504

55. Sonderstrup G, McDevitt H (1998) Identification of autoantigen epitopes in MHC class II transgenic mice. Immunol Rev 164:129-138

56. Sonderstrup G, Cope AP, Patel S et al. (1999) HLA class II transgenic mice: models of the human CD4+ T-cell immune response. Immunol Rev 172:335-343

57. Yamamoto K, Fukui Y, Esaki Y et al. (1994) Functional interaction between human histocompatibility leukocyte antigen (HLA) class II and mouse CD4 molecule in antigen recognition by $\mathrm{T}$ cells in HLA-DR and DQ transgenic mice. J Exp Med 180:165-171
58. Wen L, Wong FS, Burkly L et al. (1998) Induction of insulitis by glutamic acid decarboxylase peptide-specific and HLA-DQ8-restricted CD4(+) T cells from human DQ transgenic mice. J Clin Invest 102:947-957

59. Abraham RS, David CS (2000) Identification of HLAclass-II-restricted epitopes of autoantigens in transgenic mice. Curr Opin Immunol 12:122-129

60. Abraham RS, Kudva YC, Wilson SB, Strominger JL, David CS (2000) Co-expression of HLA DR3 and DQ8 results in the development of spontaneous insulitis and loss of tolerance to GAD65 in transgenic mice. Diabetes 49:548-554

61. Altmann DM, Douek DC, Frater AJ, Hetherington CM, Inoko H, Elliott JI (1995) The T cell response of HLA-DR transgenic mice to human myelin basic protein and other antigens in the presence and absence of human CD4. J Exp Med 181:867-875

62. Liu J, Purdy LE, Rabinovitch S, Jevnikar AM, Elliott JF (1999) Major DQ8-restricted T-cell epitopes for human GAD65 mapped using human CD4, DQA1*0301, DQB $1 * 0302$ transgenic IA(null) NOD mice. Diabetes 48:469-477

63. Cosgrove D, Gray D, Dierich A et al. (1991) Mice lacking MHC class II molecules. Cell 66:1051-1066

64. Wicker LS, Chen SL, Nepom GT et al. (1996) Naturally processed $\mathrm{T}$ cell epitopes from human glutamic acid decarboxylase identified using mice transgenic for the type $1 \mathrm{di}-$ abetes-associated human MHC class II allele, DRB1*0401. $\mathrm{J}$ Clin Invest 98:2597-2603

65. Patel SD, Cope AP, Congia M et al. (1997) Identification of immunodominant $\mathrm{T}$ cell epitopes of human glutamic acid decarboxylase 65 by using HLA-DR(alpha1*0101, beta $1 * 0401)$ transgenic mice. Proc Natl Acad Sci USA 94:8082-8087

66. Boyton RJ, Lohmann T, Londei M et al. (1998) Glutamic acid decarboxylase $\mathrm{T}$ lymphocyte responses associated with susceptibility or resistance to type I diabetes: analysis in disease discordant human twins, non-obese diabetic mice and HLA-DQ transgenic mice. Int Immunol 10:1765-1776

67. Herman AE, Tisch RM, Patel SD et al. (1999) Determination of glutamic acid decarboxylase 65 peptides presented by the type I diabetes-associated HLA-DQ8 class II molecule identifies an immunogenic peptide motif. J Immunol 163:6275-6282

68. Geluk A, Meijgaarden KE van, Schloot NC, Drijfhout JW, Ottenhoff TH, Roep BO (1998) HLA-DR binding analysis of peptides from islet antigens in IDDM. Diabetes 47:1594-1601

69. Abraham RS, Wen L, Marietta EV, David CS (2001) Type 1 diabetes-predisposing MHC alleles influence the selection of glutamic acid decarboxylase (GAD) 65-specific $\mathrm{T}$ cells in a transgenic model. J Immunol 166:1370-1379

70. Abraham RS, Wilson SB, Souza NF de Jr, Strominger JL, Munn SR, David CS (1999) NOD background genes influence $\mathrm{T}$ cell responses to GAD 65 in HLA-DQ8 transgenic mice. Hum Immunol 60:583-590

71. Raju R, Munn SR, David CS (1997) T cell recognition of human pre-proinsulin peptides depends on the polymorphism at HLA DQ locus: a study using HLA DQ8 and DQ6 transgenic mice. Hum Immunol 58:21-29

72. Congia M, Patel S, Cope AP, De Virgiliis S, Sonderstrup G (1998) $\mathrm{T}$ cell epitopes of insulin defined in HLA-DR4 transgenic mice are derived from preproinsulin and proinsulin. Proc Natl Acad Sci USA 95:3833-3838

73. Kudva YC, Deng YJ, Govindarajan R et al. (2001) HLADQ8 transgenic and NOD mice recognize different epitopes within the cytoplasmic region of the tyrosine phosphatase-like molecule, IA-2. Hum Immunol 62:1099-1105 
74. Hugues S, Mougneau E, Ferlin W et al. (2002) Tolerance to islet antigens and prevention from diabetes induced by limited apoptosis of pancreatic beta cells. Immunity 16:169-181

75. Wong FS, Janeway CA Jr (1999) The role of CD4 vs CD8 T cells in IDDM. J Autoimmun 13:290-295

76. Guerder S, Picarella DE, Linsley PS, Flavell RA (1994) Costimulator B7-1 confers antigen-presenting-cell function to parenchymal tissue and in conjunction with tumor necrosis factor alpha leads to autoimmunity in transgenic mice. Proc Natl Acad Sci USA 91:5138-5142

77. Wen L, Wong FS, Tang J et al. (2000) In vivo evidence for the contribution of human histocompatibility leukocyte antigen (HLA)-DQ molecules to the development of diabetes. J Exp Med 191:97-104

78. Rajagopalan G, Kudva YC, Chen L, Wen L, David CS (2003) Autoimmune diabetes in HLA-DR3/DQ8 transgenic mice expressing the co-stimulatory molecule B7-1 in the beta cells of islets of Langerhans. Int Immunol 15:1035-1044

79. Wen L, Chen NY, Tang J, Sherwin R, Wong FS (2001) The regulatory role of DR4 in a spontaneous diabetes DQ8 transgenic model. J Clin Invest 107:871-880

80. Lipes M (2002) Differential progression to diabetes in human DQ8 transgenic mice. Diabetes Metab Res Rev 18:S2

81. Stephens LA, Kay TW (1995) Pancreatic expression of B7 co-stimulatory molecules in the non-obese diabetic mouse. Int Immunol 7:1885-1895

82. Stewart TA, Hultgren B, Huang X, Pitts-Meek S, Hully J, MacLachlan NJ (1993) Induction of type I diabetes by interferon-alpha in transgenic mice. Science 260:19421946

83. Todd JA, Mijovic C, Fletcher J, Jenkins D, Bradwell AR, Barnett AH (1989) Identification of susceptibility loci for insulin-dependent diabetes mellitus by trans-racial gene mapping. Nature 338:587-589

84. Nepom BS, Schwarz D, Palmer JP, Nepom GT (1987) Transcomplementation of HLA genes in IDDM. HLADQ alpha- and beta-chains produce hybrid molecules in DR3/4 heterozygotes. Diabetes 36:114-117

85. Moustakas AK, Papadopoulos GK (2002) Molecular properties of HLA-DQ alleles conferring susceptibility to or protection from insulin-dependent diabetes mellitus: Keys to the fate of islet $\beta$ cells. Am J Med Genet 115:37-47

86. Kudva YC, Rajagopalan G, Raju R et al. (2002) Modulation of insulitis and type 1 diabetes by transgenic HLADR3 and DQ8 in NOD mice lacking endogenous MHC class II. Hum Immunol 63:987-999

87. Undlien DE, Thorsby E (2001) HLA associations in type 1 diabetes: merging genetics and immunology. Trends Immunol 22:467-469

88. Sheehy MJ (1992) HLA and insulin-dependent diabetes. A protective perspective. Diabetes 41:123-129

89. Undlien DE, Friede T, Rammensee HG et al. (1997) HLA-encoded genetic predisposition in IDDM: DR4 subtypes may be associated with different degrees of protection. Diabetes 46:143-149
90. Okazaki T, Pendleton CD, Lemonnier F, Berzofsky JA (2003) Epitope-enhanced conserved HIV-1 peptide protects HLA-A2-transgenic mice against virus expressing HIV-1 antigen. J Immunol 171:2548-2555

91. Corbet S, Nielsen HV, Vinner L et al. (2003) Optimization and immune recognition of multiple novel conserved HLA-A2, human immunodeficiency virus type 1-specific CTL epitopes. J Gen Virol 84:2409-2421

92. Himoudi N, Abraham JD, Fournillier A et al. (2002) Comparative vaccine studies in HLA-A2.1-transgenic mice reveal a clustered organization of epitopes presented in hepatitis $C$ virus natural infection. J Virol 76:12735-12746

93. Pancholi P, Perkus M, Tricoche N, Liu Q, Prince AM (2003) DNA immunization with hepatitis C virus (HCV) polycistronic genes or immunization by HCV DNA priming-recombinant canarypox virus boosting induces immune responses and protection from recombinant $\mathrm{HCV}$ vaccinia virus infection in HLA-A2.1-transgenic mice. J Virol 77:382-390

94. Cheuk E, D'Souza C, Hu N, Liu Y, Lang H, Chamberlain JW (2002) Human MHC class I transgenic mice deficient for $\mathrm{H} 2$ class I expression facilitate identification and characterization of new HLA class I-restricted viral T cell epitopes. J Immunol 169:5571-5580

95. Carmon L, El-Shami KM, Paz A et al. (2000) Novel breast-tumor-associated MUC1-derived peptides: characterization in $\mathrm{Db}-/-\mathrm{x}$ beta 2 microglobulin (beta2m) null mice transgenic for a chimeric HLA-A2.1/Db-beta2 microglobulin single chain. Int J Cancer 85:391-397

96. Firat H, Garcia-Pons F, Tourdot S et al. (1999) H-2 class I knockout, HLA-A2.1-transgenic mice: a versatile animal model for preclinical evaluation of antitumor immunotherapeutic strategies. Eur J Immunol 29:31123121

97. Breban M, Falgarone G, Blanchard H, Dernis-Labous E, Lamarque D (2000) Animal models of the spondyloarthropathies. Curr Rheumatol Rep 2:282-287

98. Khare SD, Bull MJ, Hanson J, Luthra HS, David CS (1998) Spontaneous inflammatory disease in HLA-B27 transgenic mice is independent of MHC class II molecules: a direct role for B27 heavy chains and not B27-derived peptides. J Immunol 160:101-106

99. Noble JA, Valdes AM, Bugawan TL, Apple RJ, Thomson G, Erlich HA (2002) The HLA class I A locus affects susceptibility to type 1 diabetes. Hum Immunol 63:657664

100. Marron MP, Graser RT, Chapman HD, Serreze DV (2002) Functional evidence for the mediation of diabetogenic $\mathrm{T}$ cell responses by HLA-A2.1 MHC class I molecules through transgenic expression in NOD mice. Proc Natl Acad Sci USA 99:13753-13758

101. Rosmalen JG, Leenen PJ, Pelegri C, Drexhage HA, Homo-Delarche F (2002) Islet abnormalities in the pathogenesis of autoimmune diabetes. Trends Endocrinol Metab 13:209-214

102. Atkinson MA, Leiter EH (1999) The NOD mouse model of type 1 diabetes: as good as it gets? Nat Med 5:601-604 